\title{
Energy-Saving and Sustainable Separation of Bioalcohols by Adsorption on Bone Char
}

\author{
Oslery Becerra-Pérez, ${ }^{1}$ Stavros Georgopoulos, ${ }^{2}$ Maria Lanara, ${ }^{2}$ \\ Hilda Elizabeth Reynel-Ávila, ${ }^{1,3}$ Maria Papadaki, ${ }^{2}$ Adrián Bonilla-Petriciolet $\mathbb{D}^{1},{ }^{1}$ \\ and Didilia Ileana Mendoza-Castillo ${ }^{1,3}$ \\ ${ }^{1}$ Instituto Tecnológico de Aguascalientes, Aguascalientes 20256, Mexico \\ ${ }^{2}$ University of Patras, Patras 30100, Greece \\ ${ }^{3}$ CONACYT, Cátedras Jóvenes Investigadores, Cd. México, 03940, Mexico
}

Correspondence should be addressed to Adrián Bonilla-Petriciolet; petriciolet@hotmail.com

Received 16 October 2020; Revised 25 November 2020; Accepted 4 December 2020; Published 15 January 2021

Academic Editor: Stefano Salvestrini

Copyright (C) 2021 Oslery Becerra-Pérez et al. This is an open access article distributed under the Creative Commons Attribution License, which permits unrestricted use, distribution, and reproduction in any medium, provided the original work is properly cited.

\begin{abstract}
The separation of ethanol, propanol, and butanol from aqueous solutions was studied using adsorption on bone char. Adsorption kinetics and thermodynamic parameters of this separation method were studied at different conditions of $\mathrm{pH}$ and temperature. Results showed that the maximum adsorption capacities of these bioalcohols were obtained at $\mathrm{pH} 6$ and $20^{\circ} \mathrm{C}$. An exothermic separation was identified, which can be mainly associated to hydrophobic interactions between bone char surface and bioalcohols. Binary adsorption studies were also performed using mixtures of these bioalcohols. An antagonistic adsorption was observed for all bioalcohols where the ethanol and propanol separation was significantly affected by butanol. A model based on an artificial neural network was proposed to correlate both single and binary adsorption isotherms of these bioalcohols with bone char. It was concluded that the bone char could be an interesting adsorbent for the sustainable separation and recovery of bioalcohols from fermentation broths, which are actually considered emerging liquid biofuels and relevant industrial chemicals.
\end{abstract}

\section{Introduction}

The reserves of conventional fuels are depleting due to their excessive exploitation, which is blamed for several environmental problems; furthermore, some concerns have raised in geopolitical security of oil supply [1-3]. Therefore, it is crucial to develop renewable, cost-effective, and alternative sustainable fuels to overcome these challenges.

Biofuels are considered the most environmentally friendly energy source. Liquid biofuels have been studied as a future leading alternative of energy to replace fossil fuels [4]. Production of liquid biofuels includes a variety of approaches (e.g., sugar fermentation, cellulose hydrolysis, biomass pyrolysis and gasification, and oil esterification/transesterification) that differ in terms of their advantages and disadvantages, but all of them undoubtedly have a low environmental impact [4-9]. Therefore, liquid biofuels pro- duction can involve several steps where the purification and recovery of final products are relevant factors to compare and select the best process for commercialization and potential applications at industrial level [3].

Bioalcohols $\mathrm{C}_{2}-\mathrm{C}_{4}$ can serve as multipurpose chemical feedstocks including their application as alternative liquid biofuels [10]. For example, ethanol is utilized in the manufacture of cosmetics, pharmaceuticals, and alcoholic beverages [11]. Propanol is also an important solvent, an intermediate for the production of several esters and amines and as a precursor for propylene production [12]. On the other hand, butanol is a solvent and extract of drugs and natural substances such as antibiotics, hormones, and vitamins [13]; it is also an important chemical precursor for paints, polymers, and plastics [14].

Fermentation is a cost-effective route to obtain these bioalcohols in the context of biorefineries $[15,16]$. However, 
this process suffers of a limited product yield generating fermentation broths with a final low alcohol concentration (around 1-2\%), which constraints the product(s) separation and its operating conditions $[13,17]$. Note that the separation costs can be increased if energy-intensive methods are utilized to recover the bioalcohols [18]. Therefore, sustainable, energy-saving, and low-cost technologies are required for the purification of these liquid biofuels. The recovery stage is paramount since separation processes represent the major production costs in biorefineries (about 20-50\%) [19]. Distillation is the conventional method employed to separate the components from fermentation broths, but it is energy-intensive with high operating cost and also contributes to $\mathrm{CO}_{2}$ emissions [17]. Furthermore, the separation of ethanol, propanol, and butanol from aqueous solutions is also challenging because the systems water + alcohol show azeotropes that could limit the separation performance by simple distillation and, consequently, intensified separation processes should be required [20]. Improvements on the separation and purification technologies can reduce the overall production costs and mitigate the environmental impact of biofuels production, especially if separation methods with low energy consumption are used for this purpose.

Adsorption is an alternative to recover liquid biofuels obtained from a variety of processing routes. This separation method is an energy-saving and environmentally friendly method in which the adsorbents used as separation medium can be regenerated and reused thus reducing the purification costs and environmental impact $[17,21]$. Selective separations, not feasible by other methods, can be performed by adsorption. Moreover, adsorption can also offer additional operational and economic advantages. To develop an effective and reliable adsorption process for biofuels recovery, it is important to identify a suitable adsorbent for the separation of the target compound(s), which will be followed by a comprehensive study of its key properties and the main adsorption parameters from kinetics, equilibrium, and desorption experiments [17]. There are studies reported in the literature covering the application of adsorbents for alcohols separation, and they include resins [22], zeolites [23] and activated carbons [17]. For example, Nielsen et al. [22] analyzed the adsorption of ethanol, iso-propanol, n-propanol, iso-butanol, n-butanol, 2-methyl-1-butanol, 3-methyl1-butanol, and n-pentanol using six resins as adsorbents. These authors found that the adsorbents with nonpolar structure and high specific surface area achieved the highest alcohol adsorption. It was also demonstrated that the longer chain alcohols were more adsorbed due to their increasingly hydrophobic nature. On the other hand, Xue et al. [21] evaluated the adsorption capacity of nine different adsorbents (i.e., activated carbon Norit ROW 0.8, ion exchange resins Amberlite IRA-900, Amberlite XAD-4, Diaion HP-2MG, Diaion HP-20, Dowex Optipore L-493, Dowex Optipore SD-2, and zeolites CBV901 and CBV28014) for the butanol recovery from aqueous solutions. Activated carbon was the best adsorbent to perform the alcohol adsorption from a fed-batch fermentation thus producing $54.6 \mathrm{~g} / \mathrm{L}$ of butanol.

Evidently, the bioalcohol recovery could be feasible with a wide variety of adsorbents. However, to the best of the authors' knowledge, few studies have determined kinetic, equilibrium, and thermodynamic parameters of bioalcohol separation via adsorption at different operating conditions to support a reliable process design. This study reports the adsorption of ethanol, propanol, and butanol from aqueous solutions using bone char as an alternative purification medium. The performance of this bioalcohol separation strategy was evaluated at different $\mathrm{pH}$ and temperatures to obtain the main adsorption parameters. Binary separation of these compounds was also studied to determine the impact of coadsorbate on bioalcohol recovery, and an artificial neural network model was proposed to predict both single and binary adsorption isotherms. Therefore, the contribution of the present paper relies on the following: (1) to report new experimental data of bioalcohol adsorption using bone char, (2) to calculate kinetic and thermodynamic parameters for the bioalcohol(s) adsorption, (3) to introduce an alternative adsorption model based on artificial neural network for simulating the binary adsorption isotherms of bioalcohols, and (4) to analyze the corresponding adsorption mechanism involved in the separation and recovery of bioalcohols from aqueous solutions using bone char. Results of this study can be used to develop alternative and non-energy intensive separation processes to recover bioalcohols for their use as biofuels and other industrial applications.

\section{Methodology}

2.1. Bioalcohol Separation with Bone Char. In this work, the efficiency of a commercial bone char as adsorbent for the recovery of bioalcohol molecules that can be produced during fermentation processes was evaluated. This adsorbent was supplied by the Brazilian company Bonechar Carvao Ativado do Brasil Ltda. Table 1 displays some relevant physicochemical properties of this adsorbent, which were provided by the supplier and verified in previous studies [24]. This adsorbent can be obtained from the pyrolysis or carbonization of bone wastes [25]. Bone char was washed with deionized water, dried at $110^{\circ} \mathrm{C}$ during $24 \mathrm{~h}$, and sieved to obtain adsorbent particles with a mean size of 0.297$0.42 \mathrm{~mm}$. These adsorbent particles were then utilized in the studies of bioalcohol recovery from the solution.

The main functional groups of bone char were analyzed, before and after the bioalcohol adsorption, via FTIR spectroscopy with a Thermo Scientific Nicolet iS10 FTIR spectrophotometer. FTIR spectra were recorded in the region 4000 to $400 \mathrm{~cm}^{-1}$ with a resolution of $4 \mathrm{~cm}^{-1}$. Thirty two (32) scans were performed for each sample. Bone char samples were measured as pellets using $\mathrm{KBr}$. Scanning Electron Microscopy (SEM) micrographs of this adsorbent were obtained using a Zeiss DSM 942 SEM equipment where the samples were covered with gold using Denton Vacuum to observe their morphology. Crystalline structure of the adsorbent, prior and after bioalcohol separation, was also studied with an Empyrean X-ray diffractometer (Malvern-PANalytical). Bone char samples obtained from single (one alcohol in the solution) and binary (two alcohols in the solution) adsorption studies were analyzed and the diffraction pattern interpretation was carried out with the HighScore Plus software. 
TABle 1: Physicochemical properties of bone char used for the separation of bioalcohols from aqueous solutions.

\begin{tabular}{lc}
\hline Parameter & Value \\
\hline Composition: & $70-76$ \\
Hydroxyapatite (wt.\%) & $9-11$ \\
Carbon (wt.\%) & $7-9$ \\
Calcium carbonate (wt.\%) & $0.1-0.2$ \\
Calcium sulfate (wt.\%) & $<0.3$ \\
Iron as $\mathrm{Fe}_{2} \mathrm{O}_{3}$ (wt.\%) & 0.65 \\
Density $\left(\mathrm{g} / \mathrm{cm}^{3}\right)$ & 8.28 \\
$\mathrm{pH}$ & 7.50 \\
$\mathrm{pH}$ & 113.3 \\
Surface area BET $\left(\mathrm{m}^{2} / \mathrm{g}\right)$ & 110.3 \\
External surface area $\left(\mathrm{m}^{2} / \mathrm{g}\right)$ &
\end{tabular}

Data obtained from Company Bonechar Carvao ativado do Brasil Ltda. and Mendoza-Castillo et al. [24].

Ethanol, propanol, and butanol (anhydrous reagent grade supplied by J.T. Baker) were employed as model compounds representing the typical bioalcohols obtained from fermentation broths. Bioalcohol solutions were prepared using deionized water, and their $\mathrm{pH}$ was adjusted to a desirable value using diluted $\mathrm{HNO}_{3}$ or $\mathrm{NaOH}$ solutions. These aqueous solutions were utilized for all adsorption studies.

Adsorption kinetic and equilibrium experiments for the separation of these bioalcohols with bone char were performed in triplicate in batch conditions in continuously agitated $20 \mathrm{~mL}$ glass vessels. More precisely, $10 \mathrm{~mL}$ of bioalcohol aqueous solution $(V)$ and $0.05 \mathrm{~g}$ of bone char $(m)$ were placed in $20 \mathrm{~mL}$ sealed glass bottles, which were submerged in a constant temperature bath and were magnetically stirred at 120 rpm. Three identical bottles were used for each condition tested. Bioalcohol recovery by adsorption was tested at different $\mathrm{pH}(6$ and 7$)$ and temperature $\left(20\right.$ and $\left.30^{\circ} \mathrm{C}\right)$ to identify the best separation conditions. Adsorption kinetics of tested bioalcohols were performed using initial concentrations $\left(C_{0}\right)$ of 160 and $650 \mathrm{mmol} / \mathrm{L}$. Kinetic profiles of bioalcohol adsorption were quantified at operating times from 0.25 to $24 \mathrm{~h}$. The isotherm experiments for single adsorption of each alcohol were carried out with initial concentrations ranging from 10 to $2200 \mathrm{mmol} / \mathrm{L}$ depending on the tested bioalcohol. These concentration ranges were selected according to the bioalcohol solubility to reach the adsorbent saturation (see Table 2). The suspension of adsorbate solution-adsorbent was equilibrated for $24 \mathrm{~h}$ at constant temperature, and the final bioalcohol concentration $\left(C_{t}\right)$ in the solution was quantified to estimate the alcohol removal. Binary adsorption experiments were also performed where aqueous solutions of alcohol $1+$ alcohol 2 were employed. Multicomponent adsorption isotherm of alcohol 1 was obtained by varying its initial concentration but using a fixed initial concentration of alcohol 2 (i.e., 200, 400, or $600 \mathrm{mmol} / \mathrm{L}$ ) in the binary solution. 18 adsorption isotherms were quantified for the aqueous solutions of ethanol + propanol, ethanol + butanol, and propanol + butanol. These binary solutions were adjusted at $\mathrm{pH} 6$, and the same experimental procedure of single adsorption isotherms was applied at $20^{\circ} \mathrm{C}$. Note that these adsorption conditions were identified as the best for bioalcohol separation.

Bioalcohol(s) concentration in all adsorption studies was determined via gas chromatography using a Thermo Scientific Trace 1300 GC equipped with a flame ionization detector (FID) and a 5\% diphenyl-95\% dimethylarylenesiloxane TG-5 SILMS column with dimensions of $30 \mathrm{~m} \times 0.25 \mathrm{~mm} \times$ $0.25 \mu \mathrm{m}$. The conditions for the bioalcohol(s) quantification method were adapted from Sadrimajd et al. [26] and Raganati et al. [27], and they were as follows: $90^{\circ} \mathrm{C}$ of injection temperature; $24 \mathrm{~mL} / \mathrm{min}$ of split flow; $2.5 \mathrm{~mL} / \mathrm{min}$ of $\mathrm{He}$ of column flow; $300^{\circ} \mathrm{C}$ of detector temperature; and column temperature program: $40^{\circ} \mathrm{C}$ for $0.5 \mathrm{~min}, 10^{\circ} \mathrm{C} / \mathrm{min}$ to $100^{\circ} \mathrm{C}$, $20^{\circ} \mathrm{C} / \mathrm{min}$ to $200^{\circ} \mathrm{C}$, and $200^{\circ} \mathrm{C}$ for $1 \mathrm{~min}$. A linear calibration curve was used to quantify the bioalcohol concentrations. Adsorption capacities of bone char $(q(\mathrm{mmol} / \mathrm{g}))$ were calculated using a mass balance for each adsorbate (i.e., bioalcohol) in both single and binary solutions:

$$
q=\frac{C_{0}-C_{t}}{m} V
$$

2.2. Kinetics and Thermodynamic Parameters of Bioalcohol Separation Using Bone Char. Adsorption rates and thermodynamic parameters of the recovery of ethanol, propanol, and butanol via adsorption with bone char were determined. These parameters were obtained from the experimental data analysis and the application of adsorption models. Bioalcohol adsorption rates were estimated with the pseudo-first [28] and pseudo-second order [29] models, Equations (2) and (3), respectively:

$$
\begin{aligned}
& q_{t}=q_{e t}\left(1-e^{-k_{1} t}\right), \\
& q_{t}=\frac{q_{e t}^{2} k_{2} t}{1+q_{e t} k_{2} t},
\end{aligned}
$$

where $q_{t}$ is the bioalcohol adsorption capacity at time $t, q_{e t}$ is the equilibrium adsorption capacity calculated with the corresponding kinetic model, $k_{1}$ and $k_{2}$ are the estimated rate constants of bioalcohol adsorption.

Langmuir [30], Freundlich [31], and Sips [32] models, Equations (4)-(6), were employed to calculate the equilibrium parameters of bioalcohol adsorption in single aqueous solutions

$$
\begin{aligned}
& q_{e}=\frac{q_{m} b C_{e}}{1+b C_{e}}, \\
& q_{e}=k_{F} C_{e}^{1 / n F}, \\
& q_{e}=\frac{q_{s} a_{s} C_{e}^{n s}}{1+a_{s} C_{e}^{n s}},
\end{aligned}
$$

where $C_{e}$ is the bioalcohol concentration in the aqueous solution at the adsorption equilibrium, $q_{m}$ is the Langmuir monolayer adsorption capacity, $b$ is the Langmuir 
TABLE 2: Physical properties of the bioalcohols (PubChem) used in adsorption tests.

\begin{tabular}{lccc}
\hline & & Alcohol \\
Physical property & Ethanol & Propanol & 60.1 \\
Molecular weight $(\mathrm{g} / \mathrm{mol})$ & 46.07 & 1000 & 74.12 \\
Solubility $(\mathrm{g} / \mathrm{L})$ in water at $25^{\circ} \mathrm{C}$ & 1000 & 0.25 & 68 \\
Octanol/water partition coefficient $(\log$ Kow) & -0.31 & 16.1 & 0.88 \\
Dissociation constant $(\mathrm{pKa})$ at $25^{\circ} \mathrm{C}$ & 15.9 & & 16.1 \\
\hline
\end{tabular}

equilibrium constant, $k_{F}$ and $n_{F}$ are the parameters of the Freundlich equation, and $q_{S}, a_{S}$, and $n_{s}$ are the parameters of Sips equation, respectively.

Adsorption enthalpy for bioalcohol separation with bone char was estimated via the next equation:

$$
\ln K_{C}=\frac{\Delta S^{0}}{R}-\frac{\Delta H^{0}}{R T},
$$

where $\Delta H^{\circ}$ is the enthalpy change, $\Delta S^{\circ}$ is the entropy change, $K_{C}$ is the partition coefficient, $T$ is the temperature, and $R$ is the universal gas constant, respectively. Partition coefficients for bioalcohol adsorption were calculated using the next expression [33]

$$
K_{c}=\frac{\gamma_{S} C_{S}}{\gamma_{e} C_{e}},
$$

where $\gamma$ is the activity coefficient and $C_{e}$ and $C_{S}$ are the concentrations of bioalcohol in the solution and adsorbed on bone char, respectively, at equilibrium (mmol/L). $K_{c}$ values were obtained from the plot of $\ln \left(C_{S} / C_{e}\right)$ versus $C_{S}$ and extrapolating $C_{S}$ to zero where $K_{c}=C_{S} / C_{e}$ assuming that $\gamma \rightarrow 1$ [33]. Van't Hoff linear analysis of $K_{c}-T$ allowed to calculate the corresponding adsorption thermodynamic parameters.

Results of preliminary fittings showed that the Langmuir-, Sips-, Freundlich-, and Redlich-Peterson-based multicomponent isotherm equations failed to correlate the binary bioalcohol adsorption data. Therefore, an artificial neural network (ANN) model was also utilized to correlate the binary adsorption isotherms of ethanol, propanol, and butanol (see Figure 1). This surrogate adsorption model was defined as

$$
\begin{aligned}
q_{e, A l c 1} & =\sum_{i=1}^{n_{y}} y_{s, i} w_{s, i}+\theta_{s}, \\
y_{s, i} & =\frac{1}{1+e^{-y_{i}}}, \\
y_{i} & =w_{1, i} C_{0 n, A l c 2}+w_{2, i} C_{e n, A l c 1}+\theta_{y, i}, \quad i=1, \cdots, n_{y}
\end{aligned}
$$

where $q_{e, A l c 1}$ is the equilibrium adsorption capacity of bone char for alcohol 1 in the binary solution (i.e., alcohol $1+$ alcohol 2), $C_{0 n, A l c 2}$ is the normalized initial concentration of alcohol 2 in the binary solution used in the adsorption study, $C_{e n, A l c 1}$ is the normalized equilibrium concentration of alcohol
1 in the binary solution, $n_{y}$ is the number of hidden neurons, and $w_{1, i}, w_{2, i}, w_{s, i}, \theta_{s}$, and $\theta_{y, i}$ are the parameters (weights and biases) of the neuronal network model that were obtained from the experimental data regression, respectively. Concentrations $C_{0 n, A l c 2}$ and $C_{e n, A l c 1}$ were normalized in this model to obtain values between 0 and 1 where this normalization was done using the maximum values of each variable obtained from all experimental data. This ANN model was used to correlate simultaneously 18 isotherms from the binary aqueous solutions of alcohol $1+$ alcohol 2 plus the corresponding 4 adsorption isotherms of single bioalcohol solutions.

These models were fitted to experimental bioalcohol adsorption data via a nonlinear regression where a least square objective function was minimized with a global stochastic optimization method. Modeling errors and determination coefficients $R^{2}$ were calculated and compared to analyze the models performance.

\section{Results and Discussion}

3.1. Adsorption Kinetics, Isotherms, and Thermodynamics of Bioalcohol Separation with Bone Char. Figure 2 shows the adsorption kinetics of the three bioalcohols on bone char at different solution $\mathrm{pH}$ and initial adsorbate concentrations. Bioalcohol adsorption in these kinetic studies ranged from 0.20 to $7.71 \mathrm{mmol} / \mathrm{g}$ for ethanol, 0.27 to $7.85 \mathrm{mmol} / \mathrm{g}$ for propanol, and 0.50 to $9.71 \mathrm{mmol} / \mathrm{g}$ for butanol, respectively. For all tested operating conditions, the adsorption equilibrium was practically reached at $24 \mathrm{~h}$ and the adsorption kinetic profile became asymptotic due to the equilibrium condition between the bioalcohol molecules and adsorbent surface. It was estimated that $82 \%$ of the bioalcohol adsorption was achieved during the first $4-6 \mathrm{~h}$ of contact time of bone char-bioalcohol solution. This finding indicates that most of the bioalcohol adsorption occurred on the adsorbent external surface. Note that the internal surface area of bone char represents only the $6 \%$ of the total adsorbent area $\left(\sim 100 \mathrm{~m}^{2} / \mathrm{g}\right)$ and the adsorption kinetic profiles were in concordance with this result [24]. The effect of solution $\mathrm{pH}$ on the alcohol adsorption is also reported in Figure 2. It was evident that an increase in solution $\mathrm{pH}$ decreased the adsorption capacity for the three bioalcohols. This experimental finding was related to the ionization degree and solubility of tested adsorbates as well as the surface charge of bone char [34].

Table 2 shows the pKa values of three bioalcohols, and it was clear that they remained as nonionizable molecules at pH 6-7 tested in the adsorption studies [22]. It is worth mentioning that the adsorbent surface of bone char was positively 


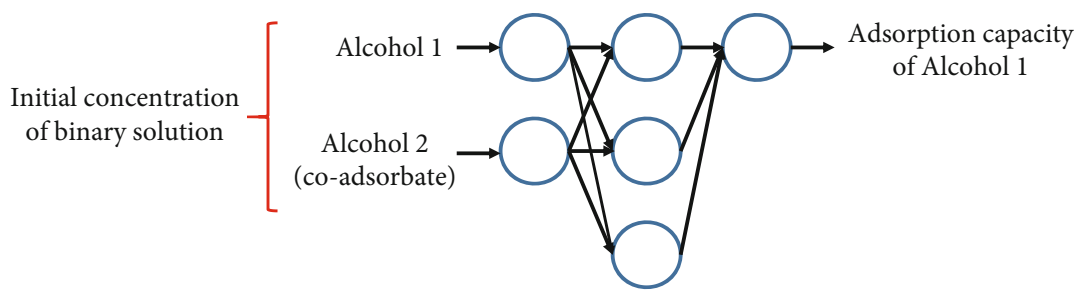

Hidden neurons

Figure 1: Artificial neural network used to model the adsorption of bioalcohols on bone char.

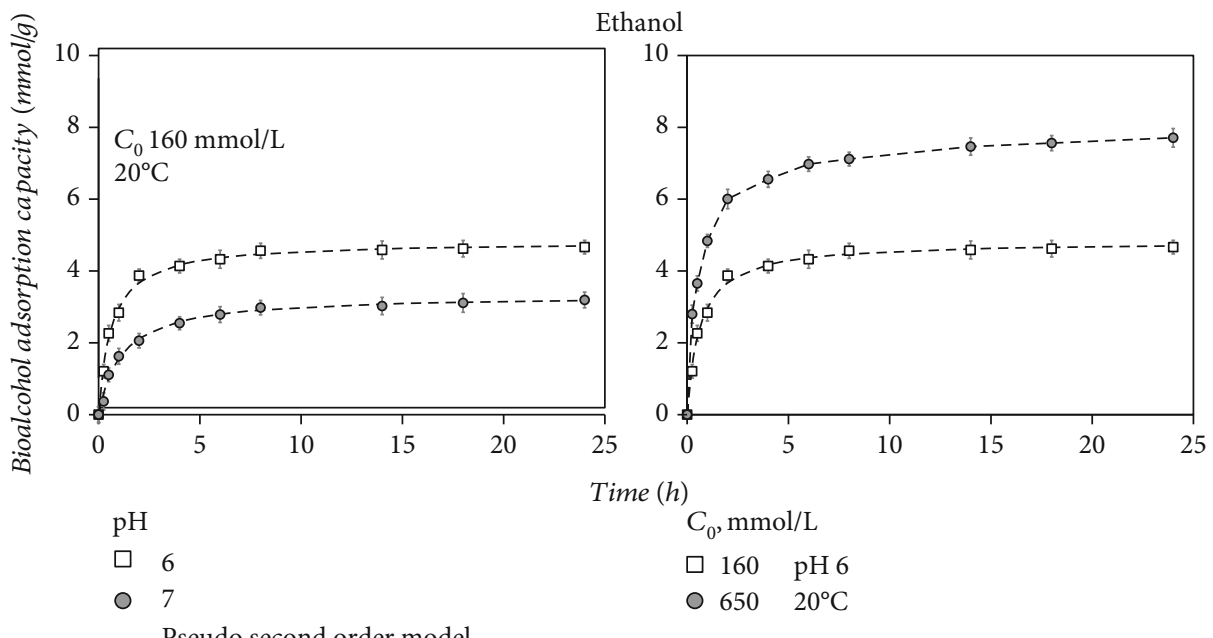

(a)

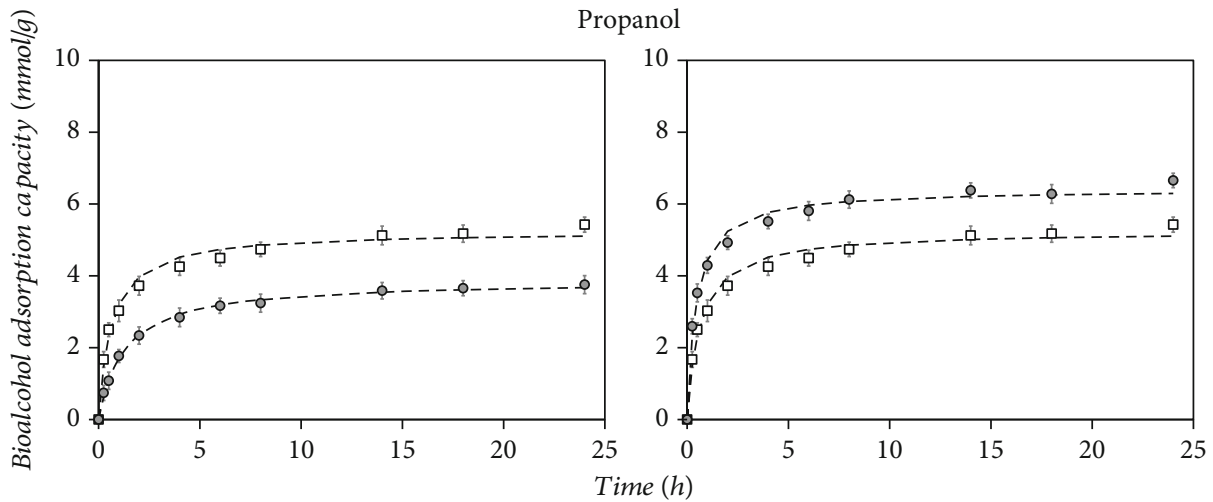

(b)

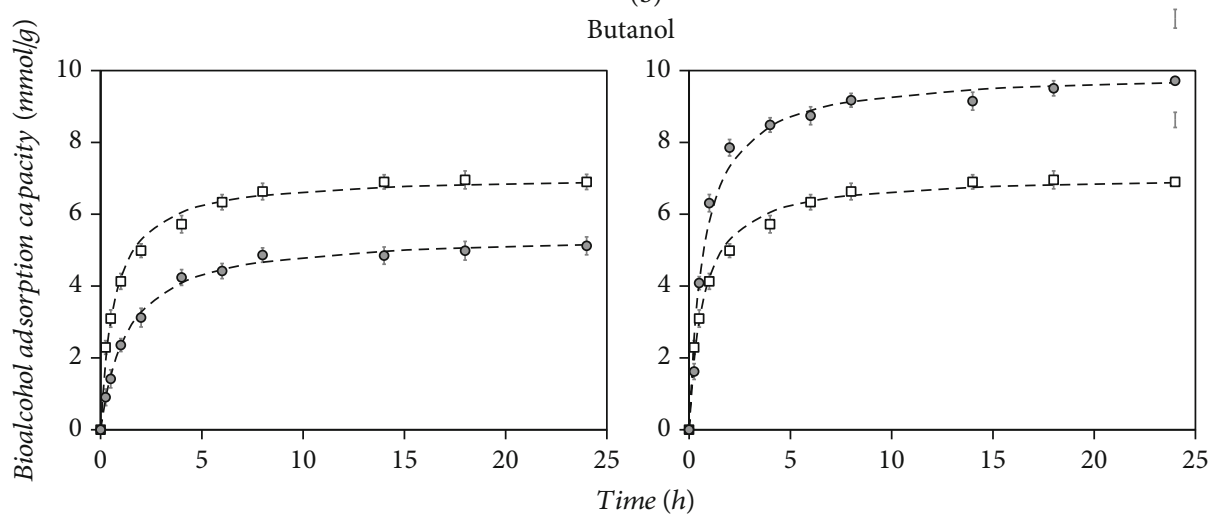

(c)

FIgURE 2: Adsorption kinetics of ethanol, propanol, and butanol from aqueous solutions with bone char as adsorbent at $20^{\circ} \mathrm{C}$. 
TABLE 3: Results of the kinetic modeling of adsorption of ethanol, propanol and butanol on bone char.

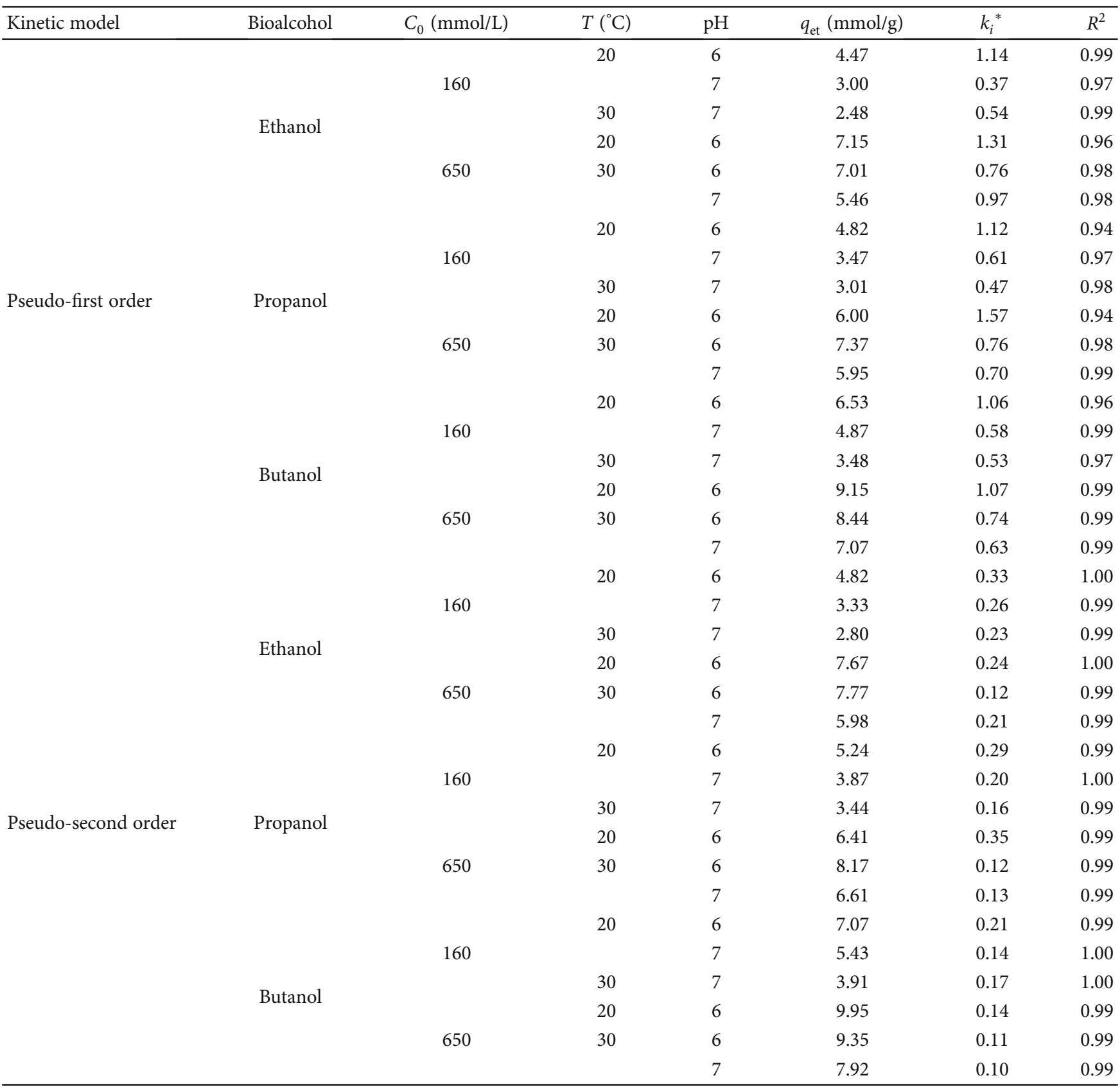

${ }^{*} k_{1}\left(\mathrm{~h}^{-1}\right)$ for pseudo-first order and $k_{2}(\mathrm{~g} / \mathrm{mmol} \mathrm{h})$ for pseudo-second order models.

charged at tested $\mathrm{pH}$ conditions due to its $\mathrm{pH}$ at the point of zero charge (i.e., $\mathrm{pH}<7.5$ ) [24].

Therefore, it could be expected that hydrophobic interactions (i.e., van der Waals forces) and hydrogen bond between bone char surface groups and bioalcohols could also take place $[22,26,35,36]$. Specifically, the strength of the hydrophobic interactions is governed by the hydrophobicity of both the solute and adsorbent. Nielsen et al. [22] stated that hydrophobic interactions can be involved in the separation of organic compounds at $\mathrm{pH}$ that is below the $\mathrm{pKa}$ of tested solute. Also, hydrogen bonds could be formed by the interaction of protonated functional groups of side chains of the adsorbent with the oxygen of bioalco- hol molecules (Lin et al., 2009; [35]; Bouiahya et al., 2019). A similar adsorption mechanism has been observed in the phenol separation with hydroxyapatite nanopowders and composites (Lin et al., 2009; Bouiahya et al., 2019). Note that the increase of $\mathrm{pH}$ from 6 to 7 resulted in the surface charge of bone char becoming less positive and, consequently, the impact of electrostatic attraction forces was reduced. Figure 2 also shows that the presence of a high content of adsorbate molecules in the aqueous solution can enhance the mass transfer increasing the bioalcohol recovery by bone char.

Calculated kinetic parameters of bioalcohol adsorption are reported in Table 3 . Statistical analysis indicated that 


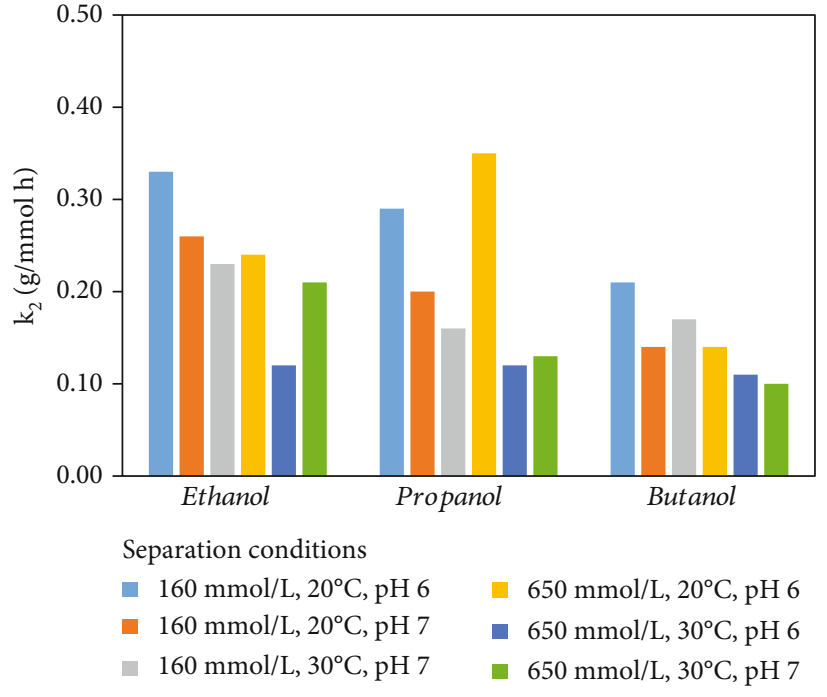

(a)

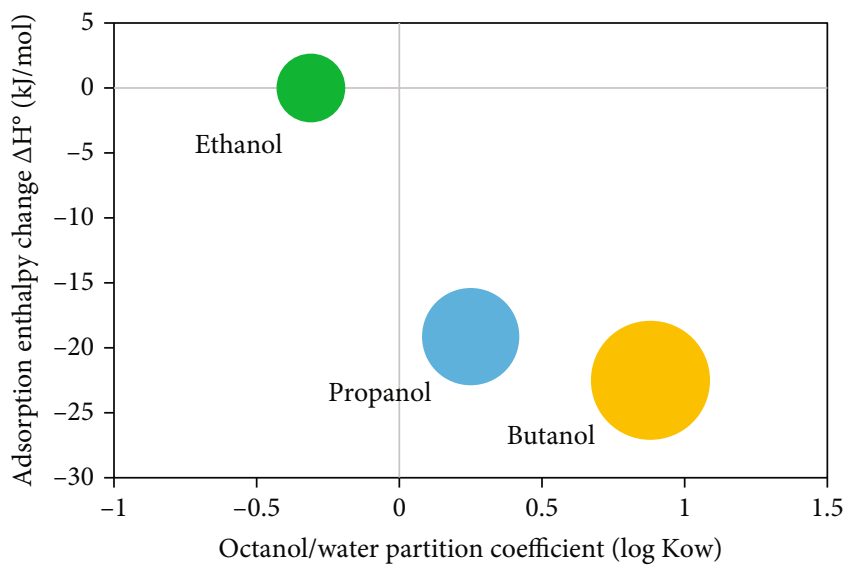

(b)

FIGURE 3: (a) Rate constants and (b) enthalpies for the adsorption of ethanol, propanol, and butanol from aqueous solution with bone char as adsorbent.

the pseudo-second order model was the best to predict the adsorption kinetic profiles for the bioalcohol removal from aqueous solutions via bone char. Determination coefficients $R^{2}$ of this kinetic model ranged from 0.99 to 1.00 , while the pseudo-first order model showed lower $R^{2}$ values (i.e., $0.94-$ 0.99). Pseudo-second order rate constants $k$ for bioalcohol separation ranged from 0.10 to $0.35 \mathrm{~g} / \mathrm{mmol} \cdot \mathrm{h}$, and they decreased with increments of $\mathrm{pH}$ and temperature, as shown in Table 3.

Kinetic parameters showed that the adsorption increased at low $\mathrm{pH}$ confirming the presence of hydrophobic interactions between bioalcohols and bone char. It was also observed that temperature decreased the adsorption kinetic rates thus indicating an exothermic separation process. Adsorption rate constants $k$ decreased with the partition coefficients $\left(\log\right.$ Kow) of tested bioalcohols where $k_{\text {ethanol }}>$ $k_{\text {propanol }}>k_{\text {butanol }}(\mathrm{g} / \mathrm{mmol} \cdot \mathrm{h})$, as shown in Figure 3(a). This result confirmed that the adsorption of butanol was faster than those obtained for propanol and ethanol, thus concluding that the butanol separation was more effective.

Adsorption isotherms of the bioalcohol separation at different $\mathrm{pH}$ and temperatures are shown in Figure 4. All isotherms of tested bioalcohols matched to the Langmuir type of Giles' classification for liquid phase adsorption [37]. Adsorption capacities increased with the initial bioalcohol concentration because of the increased driving force from the concentration gradient at the solid-liquid interphase. This phenomenon reduced the mass transfer resistance in the interphase until reaching the adsorbent saturation at tested operating conditions [38]. Maximum adsorption capacities of bone char were $8.26,8.94$, and $9.92 \mathrm{mmol} / \mathrm{g}$ for ethanol, propanol, and butanol, respectively, at $\mathrm{pH} 6$ and $20^{\circ} \mathrm{C}$, which were the best adsorption conditions tested for the recovery of these bioalcohols. As stated, the $\mathrm{pH}$ of aqueous solution affected the adsorption of three bioalcohols where the adsorption capacities decreased from 8.3 to
$15.9 \%$. However, the impact of $\mathrm{pH}$ was more pronounced for butanol recovery, which dropped by $15.9 \%$ from $\mathrm{pH} 6$ to $\mathrm{pH} 7$ at $20^{\circ} \mathrm{C}$, as shown in Figure 4 . It is important to remark that standard deviations of all experimental adsorption capacities are reported in Figures 4-6 where ANOVA indicated that the observed differences were statistically significant (i.e., $p$ level < 0.05).

This experimental finding confirmed the results of kinetic experiments and can be attributed to the fact that the global surface charge of bone char was affected by the $\mathrm{pH}$ of aqueous solution. It is worth mentioning that low $\mathrm{pH}$ favors the alcohol adsorption via hydrophobic forces, especially for long chain molecules [22]. Adsorption isotherms obtained at 20 and $30^{\circ} \mathrm{C}$ are shown in Figure 4 where an exothermic separation process was identified for all bioalcohols. Adsorption capacities decreased in 8,10 , and $12 \%$ for ethanol, propanol, and butanol, respectively, with respect to increments of solution temperature from 20 to $30^{\circ} \mathrm{C}$ at pH6. For instance, an exothermic adsorption of butanol has been also reported from 37 to $60^{\circ} \mathrm{C}$ for different adsorbents like commercial activated carbons, ion exchange resins, and zeolites [21]. Calculated adsorption enthalpies for the separation of the three bioalcohols with bone char ranged from -9.58 to $-19.37 \mathrm{~kJ} / \mathrm{mol}$, which decreased with partition coefficients where $\Delta H_{\text {butanol }}<\Delta H_{\text {propanol }}<\Delta H_{\text {ethanol }}$, as shown in Figure 3(b). These enthalpies could be associated to physisorption via noncovalent interactions such as hydrophobic forces and intermolecular hydrogen bonding, especially for butanol and propanol [36]; [35]; [26]. The calculated thermodynamic parameters indicated that the bioalcohol separation was more favorable at low adsorption temperatures. In general, it was identified that solution $\mathrm{pH}$ showed a higher impact on the bioalcohol separation with bone char than the temperature increment. Results of isotherm data modeling are reported in Table 4. Experimental adsorption isotherms were satisfactorily fitted with Sips equation, which showed the highest determination 
Ethanol
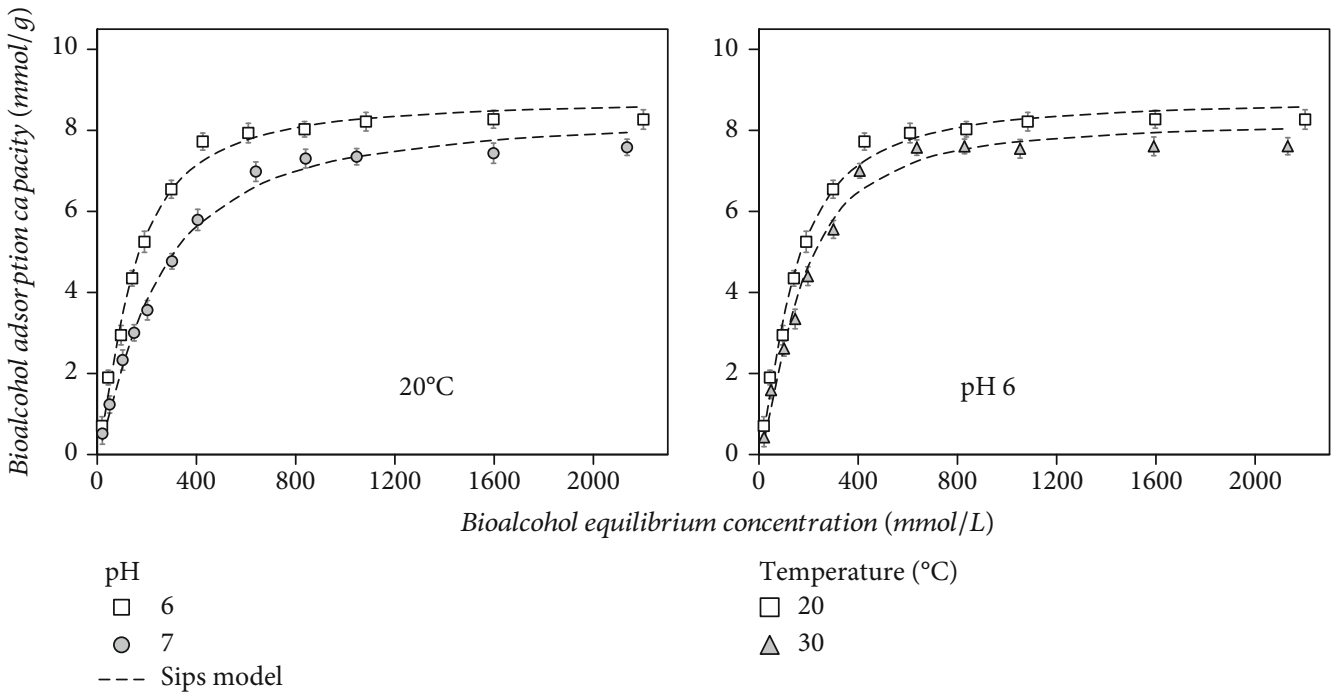

Temperature $\left({ }^{\circ} \mathrm{C}\right)$

$\triangle 30$

(a)

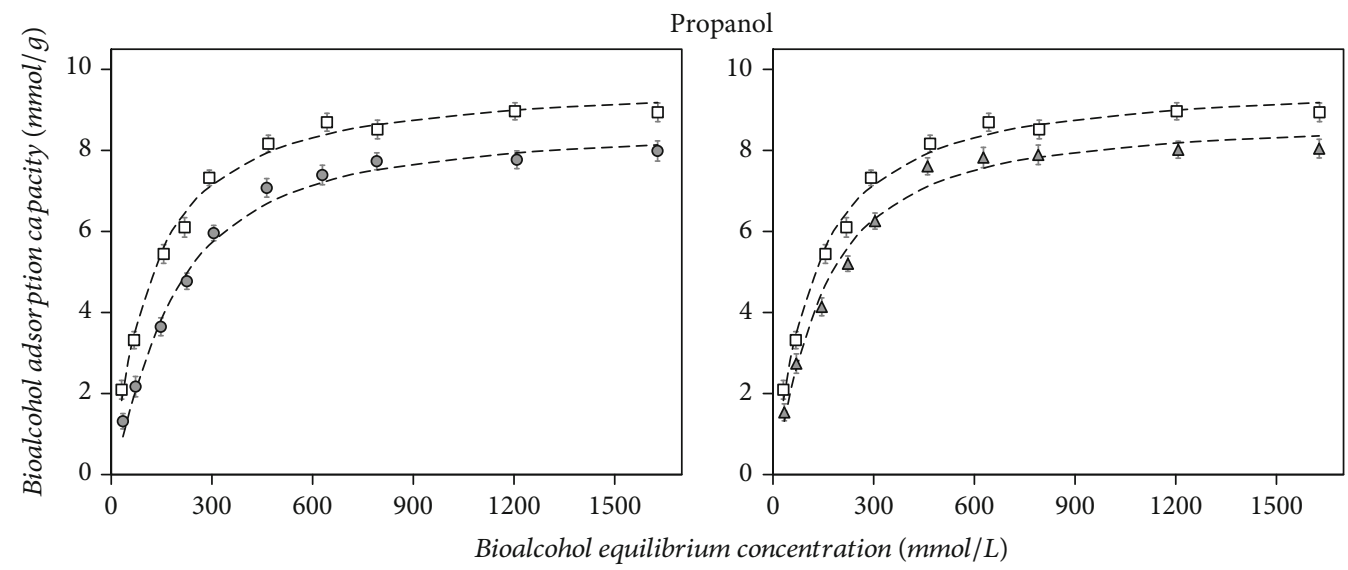

(b)

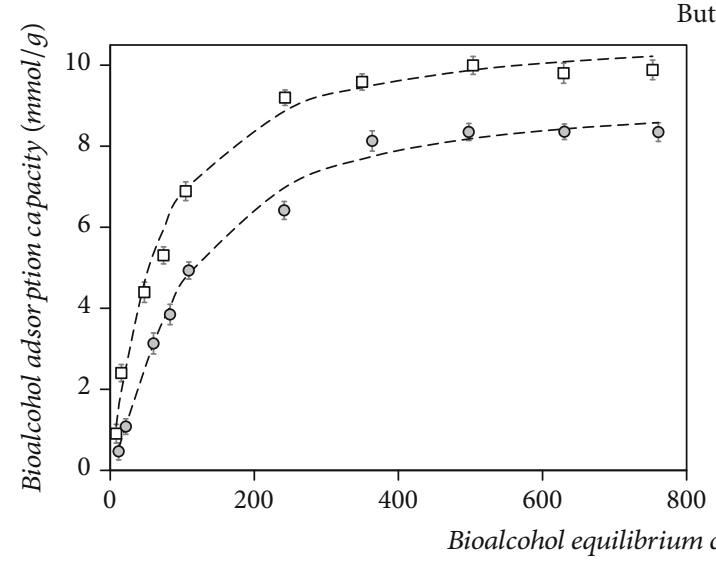

Butanol

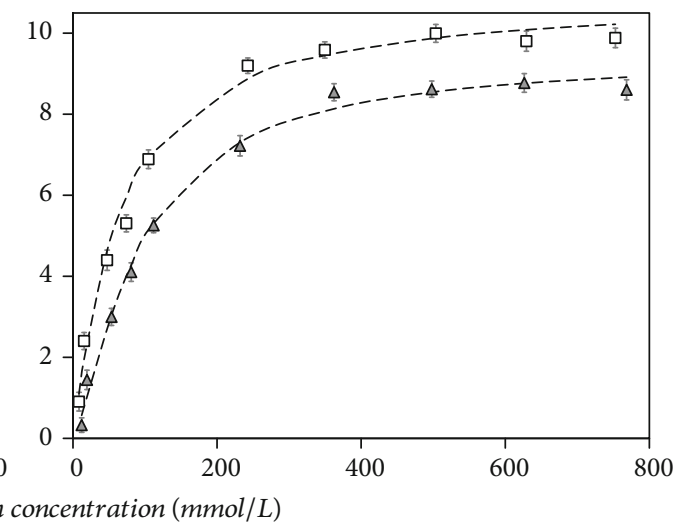

(c)

FIGURE 4: Adsorption isotherms of ethanol, propanol, and butanol on bone char in aqueous solutions at different conditions of pH and temperature.

coefficients (i.e., $R^{2} \geq 0.99$ ) for the three bioalcohols. The performance of isotherm equations to correlate bioalcohol adsorption with bone char followed the next trend: Sips > Langmuir $>$ Freundlich.
A direct relationship was observed between the hydrophobic nature of the bioalcohols and the adsorption capacities of bone char. The partition coefficients (log Kow) in the aqueous solutions were -0.26 for ethanol, 0.25 for propanol, 


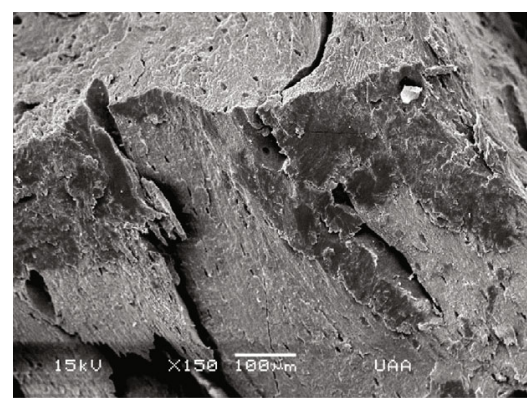

(a)

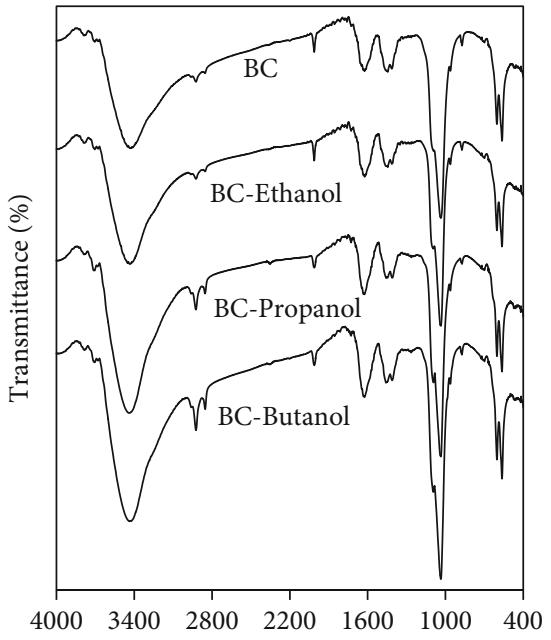

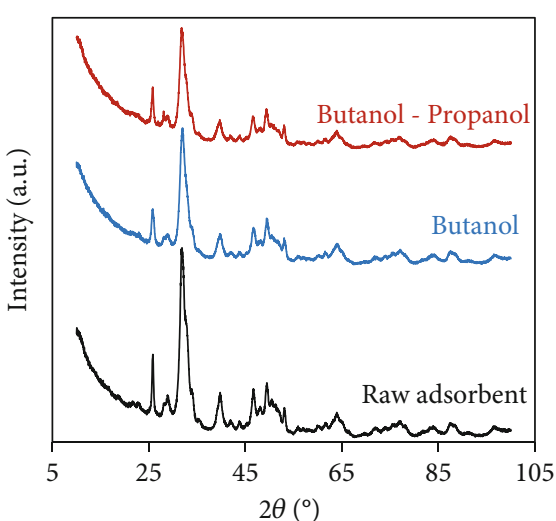

(b)

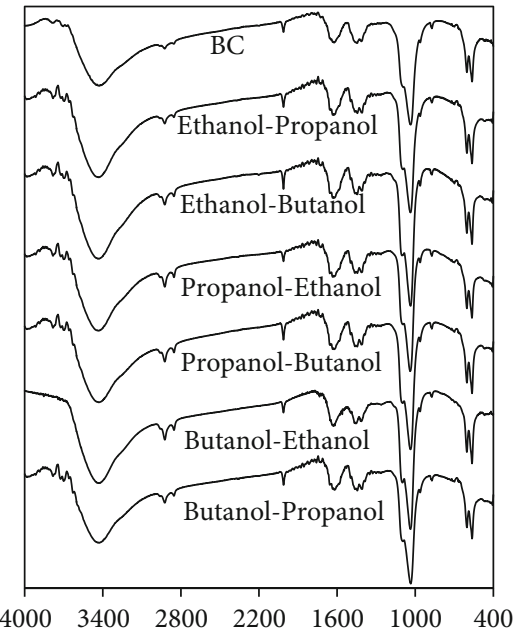

(c)

FIGURE 5: (a) SEM image, (b) X-ray diffraction, and (c) FTIR spectra of bone char used for the recovery of bioalcohols from aqueous solutions.

and 0.8 for butanol, as shown in Table 2. It is clear that the more hydrophobic compounds have higher log Kow [22]. In this case, butanol is the most hydrophobic molecule because of its longer carbon chain. Therefore, bone char showed the highest adsorption capacities for butanol, mainly due to hydrophobic interactions. Conversely, the lowest recovery was obtained for ethanol, which was the less hydrophobic bioalcohol employed in this study. These adsorption results also suggested the hydrophobic nature of the adsorbent. Similar adsorption trends have been reported by other authors using hydrophobic polymeric resins [22, 26], hydrophobic BEA-type zeolite membranes [39], and activated carbon [26].

Surface morphology of bone char corresponded to a solid phase with a rough, irregular, and compact structure besides limited pores or cavities, as the SEM images of Figure 5 show. This bone char showed a surface area of $\sim 100 \mathrm{~m}^{2} / \mathrm{g}$, which was relatively lower than those reported for other adsorbents like activated carbon. This adsorbent is mainly composed of hydroxyapatite, and consequently, its FTIR spectrum contained the characteristic absorption bands of this component, as shown in Figure 5. Principal FTIR absorption bands were identified at $3430 \mathrm{~cm}^{-1}$ (stretching mode of $\mathrm{OH}$ groups),
$2920-2850 \mathrm{~cm}^{-1}$ (CH aliphatic groups), $1630 \mathrm{~cm}^{-1}$ (C=C of aromatic rings from oxygenated groups), $1450-1385 \mathrm{~cm}^{-1}$ $\left(\mathrm{CO}_{3}\right.$ group vibrations), $1040 \mathrm{~cm}^{-1}$ (asymmetric stretching vibration of $\mathrm{PO}_{4}$ group), and $604-465 \mathrm{~cm}^{-1}$ ( $\mathrm{P}-\mathrm{O}$ vibration of $\mathrm{PO}_{4}$ group) $[25,40-43]$. The intensity of some bands changed in the FTIR spectrum of bone char after bioalcohol adsorption (see Figure 5). Specifically, the intensity of phosphate group at $1040 \mathrm{~cm}^{-1}$ decreased thus indicating its possible participation in bioalcohol adsorption [44]. On the other hand, the absorption bands of hydroxyl $\left(\sim 3430 \mathrm{~cm}^{-1}\right)$ and aliphatic $\left(2920-2850 \mathrm{~cm}^{-1}\right)$ groups broadened, increased, and slightly displaced. These changes were more evident with the increase of chain length of the alcohol adsorbed on bone char surface. The chemical structure of the bioalcohols contains an aliphatic phase and one hydroxyl group that contributed to the changes observed in FTIR spectra. X-ray diffraction results of Figure 5 also showed that the crystalline phase in all analyzed samples corresponded to the crystal planes of calcium phosphate hydroxide (ICDD-PDF2 card: 00-009-0432). However, the diffraction pattern of raw sample contained sharper peaks than the bioalcohol loaded samples thus indicating that the crystallinity decreased as the number of adsorbates on the adsorbent surface increased. 

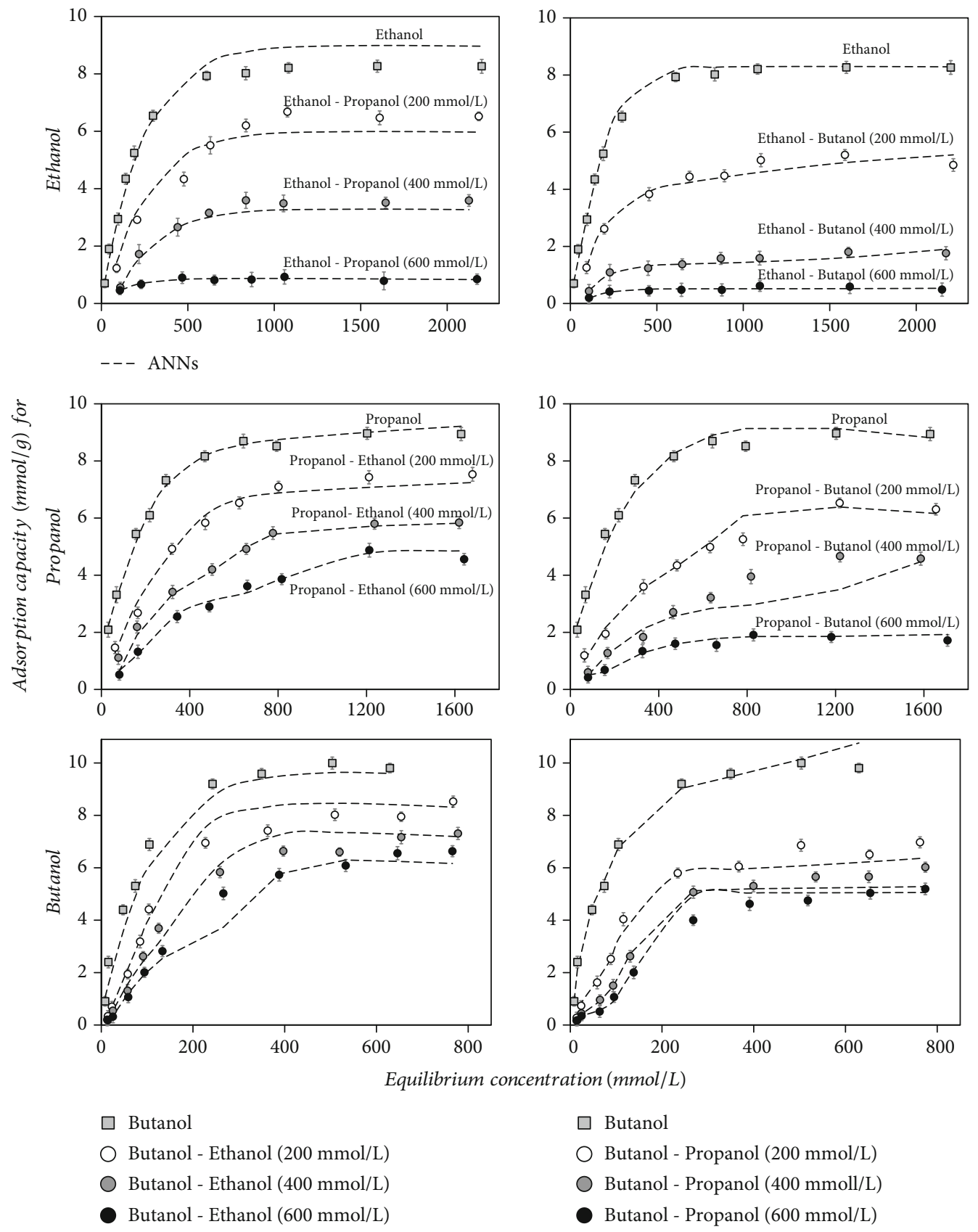

Equilibrium concentration $(\mathrm{mmol} / \mathrm{L})$

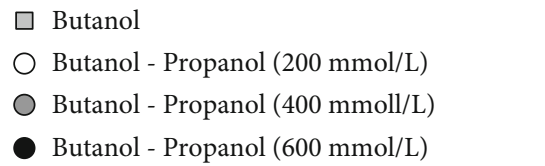

FiguRE 6: Binary adsorption isotherms of ethanol, propanol, and butanol on bone char in aqueous solutions at $\mathrm{pH} 6$ and $20^{\circ} \mathrm{C}$ and its modeling with an artificial neural network.

It is important to highlight that several studies on alcohol recovery by adsorption concluded that hydrophobic interactions were involved in the adsorption mechanism where these interactions strengthened with the increase of carbon chain length [22]; [26]. Additionally, the hydrogen bonds between $-\mathrm{OH}$ of alcohols and protonated functional groups of adsorbent surface can also contribute to alcohol adsorption on bone char [35].

3.2. Binary Bioalcohol Adsorption with Bone Char. Figure 6 shows the adsorption isotherms obtained for the separation of tested bioalcohols using binary solutions. Overall, an antagonistic adsorption was identified for all tested binary solutions where the presence of the alcohol 2 reduced the recovery of alcohol 1 . The maximum adsorption capacities were $0.49-6.52 \mathrm{mmol} / \mathrm{g}$ for ethanol, $1.72-6.31 \mathrm{mmol} / \mathrm{g}$ for propanol, and 5.19-8.53 mmol/g for butanol in binary solutions with different coadsorbate concentrations. This implied reductions from 13 to $94 \%$ with respect to the adsorption capacities determined in the single bioalcohol solutions. The impact of coadsorbate on bioalcohol adsorption was more significant for ethanol and propanol than that obtained for butanol, especially at a high concentration of alcohol 2 in the binary aqueous solution. The multicomponent bioalcohol adsorption followed the next trend: butanol $>$ propanol $>$ ethanol. These results suggested that hydrophobic 
TABLE 4: Results of the equilibrium modeling of adsorption of ethanol, propanol, and butanol on bone char.

\begin{tabular}{|c|c|c|c|c|c|}
\hline \multirow[b]{3}{*}{ Isotherm model } & \multirow[b]{3}{*}{ Parameter } & \multicolumn{4}{|c|}{ Adsorption conditions } \\
\hline & & & & & \\
\hline & & $20^{\circ} \mathrm{C}$ & $30^{\circ} \mathrm{C}$ & $20^{\circ} \mathrm{C}$ & $30^{\circ} \mathrm{C}$ \\
\hline \multicolumn{6}{|l|}{ Ethanol } \\
\hline \multirow{3}{*}{ Langmuir } & $q_{m}(\mathrm{mmol} / \mathrm{g})$ & 9.71 & 9.41 & 9.46 & 8.36 \\
\hline & $b(\mathrm{~L} / \mathrm{mmol})$ & 0.0060 & 0.0046 & 0.0034 & 0.0029 \\
\hline & $R^{2}$ & 0.97 & 0.97 & 0.99 & 0.98 \\
\hline \multirow{3}{*}{ Freundlich } & $k_{F}\left(\mathrm{mmol}^{1-1 / n F} \mathrm{~L}^{1 / \mathrm{nF}} \mathrm{g}^{-1}\right)$ & 0.81 & 0.58 & 0.40 & 0.27 \\
\hline & $n_{F}$ & 2.97 & 2.68 & 2.40 & 2.21 \\
\hline & $R^{2}$ & 0.86 & 0.86 & 0.91 & 0.90 \\
\hline \multirow{4}{*}{ Sips } & $q_{s}(\mathrm{mmol} / \mathrm{g})$ & 8.76 & 8.22 & 8.40 & 6.91 \\
\hline & $a_{s}\left(\mathrm{~L}^{\mathrm{ns}} \mathrm{mmol}^{-\mathrm{ns}}\right)$ & 0.001 & 0.00049 & 0.00089 & 0.000279 \\
\hline & $n_{S}$ & 1.40 & 1.49 & 1.29 & 1.50 \\
\hline & $R^{2}$ & 0.99 & 0.99 & 0.99 & 1.0 \\
\hline \multicolumn{6}{|l|}{ Propanol } \\
\hline \multirow{3}{*}{ Langmuir } & $q_{m}(\mathrm{mmol} / \mathrm{g})$ & 9.97 & 9.35 & 9.42 & 8.38 \\
\hline & $b(\mathrm{~L} / \mathrm{mmol})$ & 0.008 & 0.006 & 0.005 & 0.004 \\
\hline & $R^{2}$ & 0.99 & 0.98 & 0.98 & 0.98 \\
\hline \multirow{3}{*}{ Freundlich } & $k_{F}\left(\mathrm{mmol}^{1-1 / n F} \mathrm{~L}^{1 / \mathrm{nF}} \mathrm{g}^{-1}\right)$ & 1.33 & 0.96 & 0.73 & 0.57 \\
\hline & $n_{F}$ & 3.65 & 3.27 & 2.93 & 2.79 \\
\hline & $R^{2}$ & 0.87 & 0.86 & 0.88 & 0.88 \\
\hline \multirow{4}{*}{ Sips } & $q_{s}(\mathrm{mmol} / \mathrm{g})$ & 9.69 & 8.78 & 8.59 & 7.44 \\
\hline & $a_{s}\left(\mathrm{~L}^{\mathrm{ns}} \mathrm{mmol}^{-\mathrm{ns}}\right)$ & 0.0053 & 0.0024 & 0.0012 & 0.00078 \\
\hline & $n_{S}$ & 1.10 & 1.22 & 1.30 & 1.38 \\
\hline & $R^{2}$ & 0.99 & 0.99 & 1.00 & 1.00 \\
\hline \multicolumn{6}{|l|}{ Butanol } \\
\hline \multirow{3}{*}{ Langmuir } & $q_{m}(\mathrm{mmol} / \mathrm{g})$ & 11.19 & 10.60 & 10.31 & 10.10 \\
\hline & $b(\mathrm{~L} / \mathrm{mmol})$ & 0.014 & 0.008 & 0.007 & 0.0045 \\
\hline & $R^{2}$ & 0.99 & 0.98 & 0.98 & 0.98 \\
\hline \multirow{3}{*}{ Freundlich } & $k_{F}\left(\mathrm{mmol}^{1-1 / n F} \mathrm{~L}^{1 / \mathrm{nF}} \mathrm{g}^{-1}\right)$ & 1.31 & 0.69 & 0.59 & 0.30 \\
\hline & $n_{F}$ & 3.10 & 2.49 & 2.39 & 1.99 \\
\hline & $R^{2}$ & 0.91 & 0.91 & 0.93 & 0.94 \\
\hline \multirow{4}{*}{ Sips } & $q_{s}(\mathrm{mmol} / \mathrm{g})$ & 10.90 & 9.43 & 9.20 & 8.08 \\
\hline & $a_{s}\left(\mathrm{~L}^{\mathrm{ns}} \mathrm{mmol}^{-\mathrm{ns}}\right)$ & 0.011 & 0.0022 & 0.0025 & 0.00056 \\
\hline & $n_{S}$ & 1.09 & 1.35 & 1.30 & 1.52 \\
\hline & $R^{2}$ & 1.00 & 0.99 & 0.99 & 1.00 \\
\hline
\end{tabular}

interactions played a more relevant role on the simultaneous adsorption of these bioalcohols. This antagonistic adsorption of alcohols has been also reported in other studies with different adsorbents [21, 26, 27, 45-49]. Herein, it is convenient to indicate that mixtures of ethanol and butanol can be found frequently in fermentation streams. For instance, Ikegami et al. [47] analyzed the multicomponent adsorption of butanol and ethanol from $\mathrm{ABE}$ model solutions using silicone rubber-coated silicalite membranes. Results showed that butanol and ethanol recovery reduced up to 13 and 99\%, respectively, in comparison to the single adsorption showing antagonistic effects. Abdehagh et al. [46] reported that the butanol adsorption at room temperature using activated carbon F-400 was not affected by the presence of ethanol. Note that the ethanol adsorption showed a low affinity for the adsorbent. Wu et al. [49] studied the adsorption of butanol from ABE model solutions using a resin KA-I. These authors reported that the uptake of ethanol reduced significantly up to $90 \%$ in binary systems (ethanol-butanol), whereas the uptake of butanol slightly increased in $20 \%$. Also, the multicomponent adsorption of ABE model solutions using F-400 adsorbent was studied by Abdehagh et al. [45]. They found that butanol and ethanol showed a decrease in the adsorption capacities in a range of $16-50 \%$ and $50-80 \%$, respectively, in 

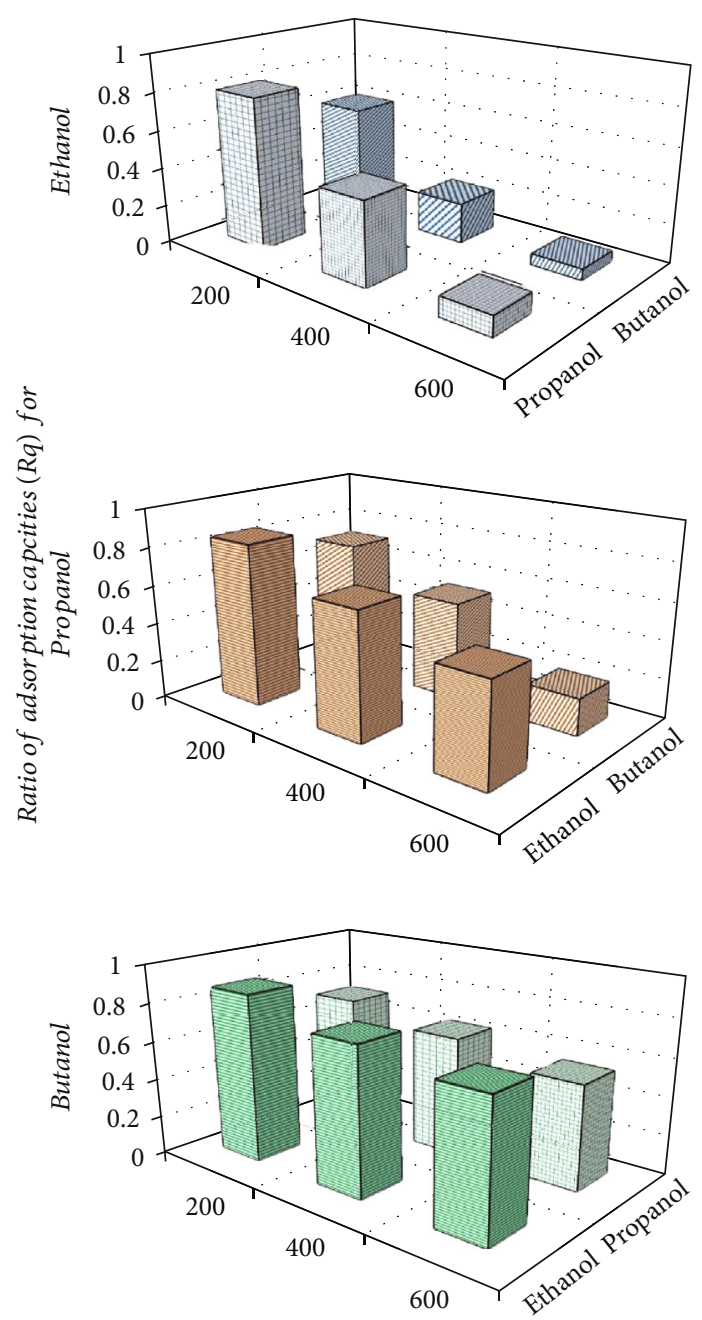

Initial concentration $(\mathrm{mmol} / \mathrm{L})$ for alcohol 2 in binary solution

FIGURE 7: Comparison of competitive adsorption of ethanol, propanol, and butanol on bone char in aqueous binary alcohol solutions at $\mathrm{pH} 6$ and $20^{\circ} \mathrm{C}$.

comparison to single adsorption tests and depending on the initial coadsorbate concentrations. Other multicomponent adsorption experiments using Norit activated carbon showed that butanol adsorption diminished in $37.5 \%$ when acetone was present in solution [21]. Raganati et al. [48] tested two amberlites and one zeolite for the adsorption of butanol from ABE model solutions. The best adsorbent was amberlite XAD-7 with single adsorption capacities of 6.08 and $3.29 \mathrm{mmol} / \mathrm{g}$ of butanol and ethanol, respectively. However, the butanol and ethanol adsorption capacities reduced in 9 and $82 \%$ in multicomponent solutions (i.e., acetone, ethanol, and butanol), thus demonstrating antagonistic adsorption effects and high selectivity for butanol. Sadrimajd et al. [26] assessed two resins and a commercial granular activated carbon for the multicomponent adsorption of butanol, ethanol and acetic acid from syngas fermentation model solution. These authors did not report the single adsorption capacities, but the butanol adsorption $(1.70 \mathrm{mmol} / \mathrm{g})$ was higher than that for ethanol $(1.21 \mathrm{mmol} / \mathrm{g})$ in multicomponent systems. Raganati et al. [27] tested the butanol recovery from ABE model solutions (acetone, butanol, ethanol, and acetic and butyric acid) using the resin amberlite XAD-7. Results showed that butanol was selectively recovered over ethanol by this resin with adsorption capacities of 1.38 and $0.09 \mathrm{mmol} / \mathrm{g}$, respectively.

On the other hand, the degree of antagonistic adsorption was analyzed via the ratio of the adsorption capacities from single and binary bioalcohols solutions

$$
R_{q}=\frac{\text { Maximum adsorption capacity in binary solution }}{\text { Maximum adsorption capacity in single solution }},
$$

where $R_{q}<1$ if the alcohol 2 reduced the adsorption of alcohol 1 in the binary solution (i.e., alcohol $1+$ alcohol 2) with respect to the results obtained in the single solution of alcohol 1 at the same operating conditions. Figure 7 shows the $R_{q}$ values calculated with the maximum adsorption capacities obtained from the experimental adsorption isotherms with single and binary solutions of tested bioalcohols. $R_{q}$ ranged from 0.06 to 0.79 for ethanol, 0.19 to 0.84 for propanol, and 0.53 to 0.87 for butanol, respectively. These values decreased as the concentration of alcohol 2 increased in the binary solution. However, butanol showed the highest values of $R_{q}$ thus indicating that its adsorption was less affected by the presence of the other co-adsorbate in the binary solution. These results confirmed that bone char was an effective adsorbent for the recovery of butanol in both single and binary bioalcohol solutions.

With respect to the surface interactions in these multicomponent adsorption tests, Figure 5 also shows the FTIR spectra of bone char samples obtained from binary adsorption studies. It was confirmed that there were an increase, enlargement, and displacement of the absorption band intensity of hydroxyl and aliphatic groups and a reduction and displacement of the phosphate group for adsorbent samples obtained from these separation experiments. However, these changes were less significant than those observed in the adsorbent samples from single bioalcohol adsorption. This result was associated with the less amount of alcohol adsorbed due to the antagonistic effect of the coadsorbate in binary solutions.

Finally, Figure 6 displays the performance of ANNs to model the binary adsorption isotherms. ANN models with different hidden neurons were tested to correlate the bioalcohol adsorption isotherms. This surrogate model provided a satisfactory fitting of experimental data with determination coefficients $R^{2}$ from 0.97 to 0.99 . Results indicated that ANNs with 3 or 4 hidden neurons was the simplest model that provided the best correlations without data overfitting. This ANN model can be utilized to predict the performance of bioalcohol separation in both single and binary solutions with this commercial bone char. Table 5 contains the parameters of the best ANN models.

3.3. Comparison of Bone Char and Other Adsorbents for Bioalcohol Separation and Some Desorption Alternatives. Table 6 provides an overview of butanol, propanol and 
TABLE 5: Parameters of ANN models to predict the adsorption of bioalcohols on bone char.

\begin{tabular}{lccccccccccccccc}
\hline \multirow{2}{*}{ Mixture } & \multirow{2}{*}{ Alcohol } & \multicolumn{1}{c}{$w_{11}$} & $w_{12}$ & $w_{21}$ & $w_{22}$ & $w_{31}$ & $w_{32}$ & $\theta_{y 1}$ & $\theta_{y 2}$ & $\theta_{y 3}$ & $w_{s 1}$ & $w_{s 2}$ & $w_{s 3}$ & $\theta_{s}$ \\
\hline Ethanol-propanol & Ethanol & -5.35 & 9.57 & 0.91 & 9.22 & 0.33 & 0.00 & 6.43 & 3.22 & 3.17 & -11.05 & 236.85 & -733.08 & 486.68 \\
Ethanol-Butanol & Ethanol & -9.79 & 2.95 & 3.09 & 18.94 & 2.37 & 0.02 & 2.46 & -0.27 & 1.32 & 2.70 & 14.15 & -27.81 & 13.51 \\
Propanol-ethanol & Propanol & -10.33 & 25.00 & 0.22 & 9.95 & 1.22 & -0.15 & -2.40 & 1.24 & 2.34 & 1.25 & 26.63 & -64.23 & 39.18 \\
Propanol-butanol & Propanol & 1.52 & 7.79 & -250.00 & 251.65 & -1.84 & -0.14 & -0.18 & -10.41 & -0.93 & 11.69 & 1.53 & 27.48 & -11.31 \\
Butanol-ethanol & Butanol & 0.70 & 6.82 & -10.73 & 25.00 & -0.49 & -0.10 & 0.95 & -0.41 & -0.54 & 29.95 & 2.47 & 32.95 & -34.30 \\
Butanol-propanol & Butanol & 2.71 & 68.36 & -2.09 & 25.36 & -4.74 & 0.71 & 0.05 & -2.97 & -4.56 & 9.57 & 4.69 & 314.22 & -9.25 \\
\hline
\end{tabular}

TABLE 6: Adsorption capacities of different adsorbents reported for the separation of bioalcohols.

\begin{tabular}{|c|c|c|c|c|c|}
\hline \multirow[b]{2}{*}{ Adsorbent } & \multirow[b]{2}{*}{ Mixture } & \multirow[b]{2}{*}{ Adsorbate } & \multicolumn{2}{|c|}{ Adsorption conditions } & \multirow[b]{2}{*}{ Reference } \\
\hline & & & $T\left({ }^{\circ} \mathrm{C}\right)$ & $\begin{array}{c}q \\
(\mathrm{mmol} / \mathrm{g})\end{array}$ & \\
\hline $\begin{array}{l}\text { High silica ZSM-5 } \\
\text { Activated carbon F-400 } \\
\text { Activated carbon BPL } \\
\text { Activated carbon X- } \\
\text { HP115 } \\
\text { Activated carbon OLC } \\
\text { Activated carbon X-A754 } \\
\text { Activated carbon M-30 }\end{array}$ & Ethanol + water & Ethanol & 32 & $\begin{array}{l}4.46 \\
1.77 \\
2.27 \\
3.25 \\
3.14 \\
4.84 \\
5.37\end{array}$ & Jones et al. [52] \\
\hline $\begin{array}{l}\text { Dowex Optipore L- } 493 \\
\text { resin }\end{array}$ & Alcohol + water in single solution & $\begin{array}{l}\text { Ethanol } \\
\text { Propanol } \\
\text { Butanol }\end{array}$ & 37 & $\begin{array}{l}1.5 \\
3.0 \\
6.0\end{array}$ & Nielsen et al. [22] \\
\hline $\begin{array}{l}\text { Metal organic framework } \\
\text { ZIF-8 }\end{array}$ & Butanol + water & Butanol & 25 & 3.89 & Remi et al. [53] \\
\hline Silica T-4722 & Ethanol + water & Ethanol & $\begin{array}{l}\text { Room } \\
\text { temperature }\end{array}$ & 2.38 & Delgado et al. [50] \\
\hline Activated carbon F-400 & Alcohol + water in single solution & $\begin{array}{l}\text { Butanol } \\
\text { Ethanol }\end{array}$ & $\begin{array}{l}\text { Room } \\
\text { temperature }\end{array}$ & $\begin{array}{l}4.05 \\
2.17\end{array}$ & Abdehagh et al. [46] \\
\hline Activated carbon F-400 & $\begin{array}{l}\text { ABE fermentation broth, breakthrough } \\
\text { experiments }\end{array}$ & $\begin{array}{c}\text { Butanol } \\
\text { Acetone } \\
\text { Ethanol } \\
\text { Acetic } \\
\text { acid } \\
\text { Butyric } \\
\text { acid }\end{array}$ & Not specified & $\begin{array}{l}4.21 \\
0.43 \\
0.15 \\
0.07 \\
0.73\end{array}$ & Abdehagh et al. [17] \\
\hline Activated carbon S4 & Ethanol + water & $\begin{array}{l}\text { Ethanol } \\
\text { Water }\end{array}$ & 25 & $\begin{array}{l}2.61 \\
18.2\end{array}$ & $\begin{array}{c}\text { Gabrus and } \\
\text { Downarowicz [51] }\end{array}$ \\
\hline $\begin{array}{l}\text { Activated carbon Norit } \\
\text { ROW0.8 }\end{array}$ & $\mathrm{ABE}$ fermentation broth & Butanol & $\begin{array}{l}37 \\
60\end{array}$ & $\begin{array}{c}6.3 \\
5.93\end{array}$ & Xue et al. [21] \\
\hline Bone char & $\begin{array}{l}\text { Ethanol + water } \\
\text { Propanol + water } \\
\text { Butanol + water }\end{array}$ & $\begin{array}{l}\text { Ethanol } \\
\text { Propanol } \\
\text { Butanol }\end{array}$ & 20 & $\begin{array}{l}8.25 \\
8.96 \\
9.92\end{array}$ & This study \\
\hline
\end{tabular}

ethanol adsorption capacities of different adsorbents reported in the literature $[17,21,22,45,46,50-53]$. It is worth noting that results reported in this table corresponded to a wide spectrum of operating conditions where broth media, high temperatures (e.g., $\sim 37^{\circ} \mathrm{C}$ ), and aqueous solutions with the presence of other compounds like acetone, acetic acid, and butyric acid have been employed in adsorption studies. These adsorption capacities are illustrative of the performance of adsorbents used for the recovery of bioalcohols, and consequently, they can be employed as a reference point for results reported in this paper. Bioalcohol adsorption capacities of bone char were higher than those obtained in single and multicomponent experiments with other adsorbents reported in the literature. In single solutions, the adsorption capacity of bone char was higher by 145 and $280 \%$ than those obtained for butanol and ethanol 
recovery with activated carbon F-400 [46], 53\% for butanol adsorption on Norit activated carbon [21], and 63 and $246 \%$ for butanol and ethanol adsorption, respectively, with resin amberlite XAD-7 [48]. For multicomponent bioalcohol adsorption, this bone char also showed higher adsorption capacities than those reported using activated carbon F-400 [45], Norit activated carbon [21], resin amberlite XAD-7 $[27,48]$, and granulated activated carbon [26]. These results indicated that bone char could be an alternative adsorbent to perform the recovery of bioalcohols from fermentation broths.

Preliminary bioalcohol desorption experiments were performed via liquid extraction (using water, acetone, and ethyl acetate) with different ratios of solvent and bone char loaded with bioalcohols. Also, a thermal desorption process was tested at different temperatures. Results indicated that the single liquid extraction with these solvents was not effective to desorb these bioalcohols from the bone char surface, while the thermal treatment was a promising strategy to perform this recovery stage. For instance, a butanol desorption of $\sim 70 \%$ was obtained at $150^{\circ} \mathrm{C}$. These preliminary findings were consistent with results of previous studies [21, 27, 36]. Levario et al. [36] reported the desorption of ethanol and butanol adsorbed on synthetic mesoporous carbons via thermal treatment at $170^{\circ} \mathrm{C}$, and they found no loss of adsorption performance after alcohol desorption. Xue et al. [21] also demonstrated the complete recovery of butanol by desorption from Norit ROW 0.8 activated carbon using a thermal desorption at $250^{\circ} \mathrm{C}$. Raganati et al. [27] tested the thermal desorption of butanol loaded on resin amberlite XAD-7 at $140^{\circ} \mathrm{C}$ achieving the complete recovery of butanol. However, a detailed study of this thermal desorption is required to identify the best conditions to recover these bioalcohols from bone char maximizing the adsorptiondesorption cycles and to optimize its corresponding separation/recovery costs.

\section{Conclusions}

The recovery of ethanol, propanol, and butanol from aqueous solutions via adsorption on bone char was analyzed at different operation conditions. Bioalcohol adsorption was affected by both $\mathrm{pH}$ and temperature of aqueous solution where the maximum adsorption was achieved at $\mathrm{pH} 6$ and $20^{\circ} \mathrm{C}$. The adsorption capacities of bone char were butanol $>$ propanol $>$ ethanol where hydrophobic interactions played a relevant role in the adsorption mechanism. Overall, the separation of these bioalcohols was an exothermic process governed by physical interaction forces. It was also concluded that the butanol adsorption by bone char was not significantly affected by the presence of ethanol or propanol in the aqueous solution. The modeling of binary adsorption of these bioalcohols can be performed with an artificial neural network, and this model can be used for process design. Preliminary studies suggested that a thermal desorption is a promising option to recover the alcohols loaded on the bone char. However, a detailed analysis of thermal desorption conditions should be performed to minimize the costs and to increase the bioalcohol recovery.
In summary, the adsorption of bioalcohols on bone char appears to be a promising and low-cost and energy-saving process for the separation and recovery of these compounds from fermentation broths.

\section{Data Availability}

Data of this paper are available on request to the corresponding author.

\section{Conflicts of Interest}

The authors declared no potential conflicts of interest with respect to the research, authorship, and/or publication of this article.

\section{Acknowledgments}

The authors acknowledge the funding received from the European Union's Horizon 2020 research and innovation programme under the Marie Sklodowska-Curie grant agreement No. 778168.

\section{References}

[1] H. B. Aditiya, T. M. I. Mahlia, W. T. Chong, H. Nur, and A. H. Sebayang, "Second generation bioethanol production: A critical review," Renewable and Sustainable Energy Reviews, vol. 66, pp. 631-653, 2016.

[2] S. H. M. Azhar, R. Abdulla, S. A. Jambo et al., "Structure and properties of hydroxyapatite/hydroxyethyl cellulose acetate composite films," Biochemistry and Biophysics Reports, vol. 10, pp. 52-61, 2017.

[3] C. Dellomonaco, F. Fava, and R. Gonzalez, "The path to next generation biofuels: successes and challenges in the era of synthetic biology," Microbial Cell Factories, vol. 9, no. 1, pp. 3-15, 2010.

[4] P. S. Nigam and A. Singh, "Production of liquid biofuels from renewable resources," Progress in Energy and Combustion Science, vol. 37, no. 1, pp. 52-68, 2011.

[5] S. Ali, O. Shafique, S. Mahmood, T. Mahmood, B. Khan, and I. Ahmad, "Biofuels production from weed biomass using nanocatalyst technology," Biomass and Bioenergy, vol. 139, p. 105595, 2020.

[6] M. Arnold, J. A. Tainter, and D. Strumsky, "Productivity of innovation in biofuel technologies," Energy Policy, vol. 124, pp. 54-62, 2019.

[7] M. Raud, T. Kikas, O. Sippula, and N. J. Shurpali, "Potentials and challenges in lignocellulosic biofuel production technology," Renewable and Sustainable Energy Reviews, vol. 111, pp. 44-56, 2019.

[8] N. Scovronick and P. Wilkinson, "Health impacts of liquid biofuel production and use: A review," Global Environmental Change, vol. 24, pp. 155-164, 2014.

[9] S. Sharma, A. Kundu, S. Basu, N. Shetti, and T. M. Aminabhavi, "Sustainable environmental management and related biofuel technologies," Journal of Environmental Management, vol. 273, p. 111096, 2020.

[10] W. Luo, Z. Zhao, H. Pan, L. Zhao, C. Xu, and X. Yu, "Feasibility of butanol production from wheat starch wastewater by 
Clostridium acetobutylicum," Energy, vol. 154, pp. 240-248, 2018.

[11] A. Demirbas, "Bioethanol from cellulosic materials: A renewable motor fuel from biomass," Energy Sources, vol. 27, no. 4, pp. 327-337, 2005.

[12] T. Walther and J. M. Francois, "Microbial production of propanol,” Biotechnology Advances, vol. 34, no. 5, pp. 984-996, 2016.

[13] Y. Ni and Z. Sun, "Recent progress on industrial fermentative production of acetone-butanol-ethanol by Clostridium acetobutylicum in China," Applied Microbiology and Biotechnology, vol. 83, no. 3, pp. 415-423, 2009.

[14] E. M. Green, "Fermentative production of butanol-the industrial perspective," Current Opinion in Biotechnology, vol. 22, no. 3, pp. 337-343, 2011.

[15] V. Aristizábal-Marulanda and C. A. A. Cardona, "Experimental production of ethanol, electricity, and furfural under the biorefinery concept," Chemical Engineering Science, vol. 229, p. 116047, 2021.

[16] I. Dávila, B. Gullón, J. Labidi, and P. Gullón, "Multiproduct biorefinery from vine shoots: Bio-ethanol and lignin production," Renewable Energy, vol. 142, pp. 612-623, 2019.

[17] N. Abdehagh, P. Gurnani, F. Tezel, and J. Thibault, "Adsorptive separation and recovery of biobutanol from ABE model solutions," Adsorption, vol. 21, no. 3, pp. 185-194, 2015.

[18] S. van Wyk, A. G. J. van der Ham, and S. R. Kersten, "Pervaporative separation and intensification of downstream recovery of acetone-butanol-ethanol (ABE)," Chemical Engineering \& Processing: Process Intensification, vol. 130, pp. 148-159, 2018.

[19] H. J. Huang, S. Ramaswamy, U. W. Tschirner, and B. V. Ramarao, "A review of separation technologies in current and future biorefineries," Separation and Purification Technology, vol. 62, no. 1, pp. 1-21, 2008.

[20] A. Kujawska, J. Kujawski, M. Bryjak, and W. Kujawski, “ABE fermentation products recovery methods-A review," Renewable and Sustainable Energy Reviews, vol. 48, pp. 648-661, 2015.

[21] C. Xue, F. Liu, M. Xu et al., "Butanol production in acetonebutanol-ethanol fermentation with _in situ_product recovery by adsorption," Bioresource Technology, vol. 219, pp. 158-168, 2016.

[22] D. Nielsen, G. S. Amarasiriwardena, and K. Prather, "Predicting the adsorption of second generation biofuels by polymeric resins with applications for in situ product recovery (ISPR)," Bioresource Technology, vol. 101, no. 8, pp. 2762-2769, 2010.

[23] F. Faisal, A. Zarebska, P. Saremi et al., "MFI zeolite as adsorbent for selective recovery of hydrocarbons from ABE fermentation broths," Adsorption, vol. 20, no. 2-3, pp. 465-470, 2014.

[24] D. I. Mendoza-Castillo, A. Bonilla-Petriciolet, and J. JáureguiRincón, "On the importance of surface chemistry and composition of bone char for the sorption of heavy metals from aqueous solution," Desalination and Water Treatment, vol. 54, pp. 1-12, 2014.

[25] C. K. Rojas-Mayorga, A. Bonilla-Petriciolet, I. A. Aguayo-Villarreal et al., "Optimization of pyrolysis conditions and adsorption properties of bone char for fluoride removal from water," Journal of Analytical and Applied Pyrolysis, vol. 104, pp. 10-18, 2013.

[26] P. Sadrimajd, E. Rene, and P. Lens, "Energy-efficient recovery of butanol from model solutions and fermenta- tion broth by adsorption," Fuel, vol. 254, article 115590, 2019.

[27] F. Raganati, A. Procentese, G. Olivieri, M. E. Russo, P. Salatino, and A. Marzocchella, "Bio-butanol recovery by adsorption/desorption processes," Separation and Purification Technology, vol. 235, p. 116145, 2020.

[28] S. Lagergren, "About the theory of so-called adsorption of soluble substances," Kungliga Svenska Vetenskapsakademiens. Handlingar, vol. 24, pp. 1-39, 1898.

[29] Y. S. Ho and G. McKay, "Pseudo-second order model for sorption processes," Process Biochemistry, vol. 34, no. 5, pp. 451465, 1999.

[30] I. Langmuir, "The adsorption of gases on plane surfaces of glass, mica and platinum," American chemical journal, vol. 40, no. 9, pp. 1361-1403, 1918.

[31] H. M. F. Freundlich, "Over the adsorption in solution," Journal of Physical Chemistry, vol. 57, pp. 385-471, 1906.

[32] R. Sips, "On the structure of a catalyst surface," Journal of Chemical Physics, vol. 16, no. 5, pp. 490-495, 1948.

[33] H. N. Tran, S. J. You, A. Hosseini-Bandegharaei, and H. P. Chao, "Mistakes and inconsistencies regarding adsorption of contaminants from aqueous solutions: A critical review," Water Research, vol. 120, pp. 88-116, 2017.

[34] T. M. Salem Attia, X. L. Hu, and D. Q. Yin, "Synthesized magnetic nanoparticles coated zeolite for the adsorption of pharmaceutical compounds from aqueous solution using batch and column studies," Chemosphere, vol. 93, no. 9, pp. 20762085, 2013.

[35] I. A. Aguayo-Villarreal, M. A. Montes-Morán, V. HernándezMontoya et al., "Importance of iron oxides on the carbons surface vs the specific surface for VOC's adsorption," Ecological Engineering, vol. 106, pp. 400-408, 2017.

[36] T. J. Levario, M. Dai, W. Yuan, B. Vogt, and D. Nielsen, "Rapid adsorption of alcohol biofuels by high surface area mesoporous carbons," Microporous and Mesoporous Materials, vol. 148, no. 1, pp. 107-114, 2012.

[37] C. H. Giles, T. H. MacEwan, S. N. Nakhwa, and D. Smith, "786. Studies in adsorption. Part XI. A system of classification of solution adsorption isotherms, and its use in diagnosis of adsorption mechanisms and in measurement of specific surface areas of solids," Journal of Chemical Society, vol. 1, pp. 3973-3993, 1960.

[38] H. Bhatti, Z. Mahmood, A. Kausar, S. Yakout, O. Shair, and M. Iqbal, "Biocomposites of polypyrrole, polyaniline and sodium alginate with cellulosic biomass: Adsorption-desorption, kinetics and thermodynamic studies for the removal of 2,4-dichlorophenol," International Journal of Biological Macromolecules, vol. 153, pp. 146-157, 2020.

[39] K. Ueno, S. Yamada, T. Watanabe et al., "Hydrophobic $*$ BEAtype zeolite membranes on tubular silica supports for alcohol/water separation by pervaporation," Membranes, vol. 9, no. 7, pp. 86-98, 2019.

[40] K. Azzaoui, E. Mejdoubi, A. Lamhamdi et al., "Structure and properties of hydroxyapatite/hydroxyethyl cellulose acetate composite films," Carbohydrate Polymers, vol. 115, pp. 170176, 2015.

[41] S. Lurtwitayapont and T. Srisatit, "Comparison of lead removal by various types of swine bone adsorbents," Environment Asia, vol. 3, pp. 32-38, 2010.

[42] F. Mohandes, M. Salavati-Niasari, M. Fathi, and Z. Fereshteh, "Hydroxyapatite nanocrystals: simple preparation, 
characterization and formation mechanism," Materials Science and Engineering, vol. 45, pp. 29-36, 2014.

[43] S. Mondal, B. Mondal, A. Dey, and S. Mukhopadhyay, "Studies on processing and characterization of hydroxyapatite biomaterials from different bio wastes," Journal of Minerals and Materials Characterization and Engineering, vol. 11, no. 1, pp. 5567, 2012.

[44] Y. Yang, C. Sun, B. Lin, and Q. Huang, "Surface modified and activated waste bone char for rapid and efficient VOCs adsorption," Chemosphere, vol. 256, article 127054, 2020.

[45] N. Abdehagh, F. H. Tezel, and J. Thibault, "Multicomponent adsorption modeling: isotherms for ABE model solutions using activated carbon F-400," Adsorption, vol. 22, no. 3, pp. 357-370, 2016.

[46] N. Abdehagh, F. H. Tezel, and J. Thibault, "Adsorbent screening for biobutanol separation by adsorption: kinetics, isotherms and competitive effect of other compounds," Adsorption, vol. 19, no. 6, pp. 1263-1272, 2013.

[47] T. Ikegami, H. Negishi, and K. Sakaki, "Selective separation of n-butanol from aqueous solutions by pervaporation using silicone rubber-coated silicalite membranes," Journal of Chemical Technology and Biotechnology, vol. 86, no. 6, pp. 845-851, 2011.

[48] F. Raganati, A. Procentese, G. Olivieri, M. E. Russo, P. Salatino, and A. Marzocchella, "Bio-butanol separation by adsorption on various materials: Assessment of isotherms and effects of other ABE-fermentation compounds," Separation and Purification Technology, vol. 191, pp. 328-339, 2018.

[49] J. Wu, W. Zhuang, H. Ying et al., “Acetone-butanol-ethanol competitive sorption simulation from single, binary and ternary systems in a fixed-bed of KA-I resin," Biotechnology Progress, vol. 31, no. 1, pp. 124-134, 2015.

[50] J. A. Delgado, M. A. Uguina, J. L. Sotelo, V. I. Águeda, A. García, and A. Roldán, "Separation of ethanol-water liquid mixtures by adsorption on silicalite," Chemical Engineering Journal, vol. 180, pp. 137-144, 2012.

[51] E. Gabrus and D. Downarowicz, "Anhydrous ethanol recovery from wet air in TSA systems - Equilibrium and column studies," Chemical Engineering Journal, vol. 288, pp. 321-331, 2016.

[52] R. A. Jones, F. H. Tezel, J. Thibault, and J. S. Tolan, "Bio-ethanol production to be blended with gasoline: Improvements in energy use by adsorption," International Journal of Energy Research, vol. 31, no. 15, pp. 1517-1531, 2007.

[53] J. Cousin Saint Remi, G. Baron, and J. Denayer, "Adsorptive separations for the recovery and purification of biobutanol," Adsorption, vol. 18, no. 5-6, pp. 367-373, 2012. 